\title{
Practice patterns of multidisciplinary team meet- ings in Korean cancer care and patient satisfaction with this approach
}

\author{
Chi Hoon Maeng ${ }^{1,}$, Hee Kyung Ahn ${ }^{2,}$, Sung Yong Oh${ }^{3}$, Seungtaek Lim ${ }^{4}$, Bong-Seog Kim ${ }^{5}$, and Do Yeun $\mathrm{Kim}^{6}$
}

\begin{abstract}
${ }^{1}$ Department of Medical Oncology and Hematology, Kyung Hee University Hospital, Seoul;

${ }^{2}$ Department of Oncology, Gachon University Gil Medical Center, Incheon; ${ }^{3}$ Department of Hematology-Oncology, Dong-A University College of Medicine, Busan; ${ }^{4}$ Department of Internal Medicine, Wonju Severance Christian Hospital, Wonju; ${ }^{5}$ Department of Internal Medicine, Veterans Health Service Medical Center, Seoul; ${ }^{6}$ Department of Internal Medicine, Dongguk University Ilsan Hospital, Goyang, Korea
\end{abstract}

\section{Received: June 10, 2019}

Revised : July 21, 2019

Accepted: July 31, 2019

\section{Correspondence to}

Do Yeun Kim, M.D.

Department of Internal Medicine, Dongguk University

Ilsan Hospital, 27 Dongguk-ro,

Ilsandong-gu, Goyang 10326,

Korea

Tel: +82-31-961-7143

Fax: +82-31-961-7141

E-mail: smdkdy@dumc.or.kr https://orcid.org/0000-00017265-1994

*These authors contributed equally to this work.
Background/Aims: The multidisciplinary team (MDT) approach is a cornerstone of clinical oncology. This study investigated the current state of MDT care, including patient satisfaction, in Korea.

Methods: We obtained the annual number of cancer patients who have received MDT care since 2014 from the registry of the Health Insurance Review and Assessment Service (HIRA). In addition, patients who received MDT care from August 2014 to May 2017 at four university hospitals were further characterized, and patient satisfaction was measured prospectively using a patient-reported questionnaire.

Results: The total number of patients who received MDT care increased from 2014 to 2016 (2,113 to 9,998 patients, respectively) in the HIRA Cohort. The type of cancer that most often required MDT was breast cancer (23.8\%), followed by colorectal cancer (19.1\%). In the Representative Cohort ( $n=1,032)$, MDT was requested by the surgeon more than half the time (55.7\%). The main focus of MDT was decision making for further treatment planning (99.0\%). The number of doctors participating in the MDT was usually five (70.0\%). After initiating an MDT approach, the treatment plan changed for $17.4 \%$ of patients. Among these patients, 359 completed a prospective satisfaction survey regarding their MDT care. The overall satisfaction with the MDT approach was very high, with an average score of 9.6 out of 10 points.

Conclusions: The application of MDT care is a rapidly growing trend in clinical oncology, and shows high patient satisfaction. Further research is needed to determine which types of cancer patients could benefit most from MDT, and to enable MDT care to operate more efficiently so that it may expand successfully throughout Korea.

Keywords: Multidisciplinary team; Patient satisfaction; Treatment outcome; Medical oncology

\section{INTRODUCTION}

Clinical treatment decisions for cancer patients often vary among physicians [1]. This is due to a wide variety of patient clinical presentations and the fragmented subspecialties among cancer specialists. In addition, these hurdles may lead to a substantial number of cancer patients seeking a second opinion [2]. Given the com- 
plexity of cancer care, the multidisciplinary team (MDT) approach is a cornerstone of optimal management. This is supported by international trends in that MDT care is mandatory in $63 \%$ of European countries and national or state-defined guidelines for the use of MDT have been implemented in the United Kingdom (UK) $[3,4]$. Furthermore, a policy statement on MDT cancer care has been released by The European Partnership for Action Against Cancer to help each individual institute establish a qualified MDT [5].

Several studies have reported that MDT-based decision making has led to changes in initial diagnoses and treatment plans, more accurate diagnoses, and even improved survival outcomes [6-9]. In Korea, the implementation of MDT care and its role in certain cancers, such as colorectal and gynecologic cancers, has been explored $[10,11]$. As shown by these data, MDT care has been actively adopted. However, these previous reports were single-center studies that focused mainly on the impact of MDT care on clinical decision making, defined as the rate of change in the treatment plan or diagnosis.

MDT-based decision making for cancer patients in Korea has been officially introduced and encouraged by the National Health Insurance Service (NHIS) since August 2014. According to a subsequent study concerning MDT care for cancer patients in Korea [12], the application of MDT care after reimbursement appears to be successful. However, this study was conducted within the first 6 months of reimbursement, which is too early to assess the overall trend for MDT care since its inception. Meanwhile, another study conducted by medical oncologists demonstrated that the proportion of MDTs involved in cancer care was less than $10 \%$. When limited to the four major types of cancer (lung, breast, stomach, and colorectal), the rate was still only $20 \%$ to $30 \%$ [13]. However, the results of that study were based on a cross-sectional survey conducted over a transient period, rather than over a sufficiently long period. Furthermore, studies that address satisfaction with MDT care from the perspective of the patient rather than the physician have not yet been reported worldwide [8]. Patient's attendance is a prerequisite for reimbursement from the NHIS, so it is important that MDT work efficiently from the patient's perspective. Taken together, no study has yet investigated the trends, overall implementation, and patient satisfaction with MDT care since reimbursement for MDT care began in Korea. In this study, we aimed to investigate the increasing trend of MDT care in clinical oncology and to examine the clinical characteristics as well as the satisfaction of cancer patients receiving MDT care in Korea.

\section{METHODS}

\section{Patients}

This study involved two cohorts. First, the annual number of cancer patients who received MDT care in Korea was obtained from the registry of the Health Insurance Review and Assessment Service (HIRA), and these patients made up the HIRA cohort. Because all cancer patients receiving MDT care in Korea have been registered in the HIRA system since August 2014, upon implementation of reimbursement for MDT care, the distribution of patients by cancer type, region, age, sex, and the total number of patients since that time can be viewed. Second, we selected four university hospitals in Korea to analyze the clinical characteristics, details of MDT care, and satisfaction with MDT care of patients in real-world practice; these patients made up the Representative Cohort. These four hospitals were selected from among the institutions that members of the Insurance and Policy Committee of Korean Society of Medical Oncology are affiliated.

Analysis of the Representative Cohort consisted of two parts. First, demographic findings and clinical characteristics, including stage, cancer type, and treatment history, were collected from August 2014 to May 2017. The detailed characteristics of MDT care included the number of attending physicians, time expended by the MDT, the patient's accompanying family members, and the aim of each MDT. For a portion of the patients, a survey on the patient's satisfaction with MDT care was conducted prospectively from September 2016 to May 2017. After leaving the care of the MDT, each subject was administered the questionnaire and allowed to respond. The protocol for the study was reviewed and approved by the Institutional Review Board (IRB) of each participating institute (Approval Number: KHUH 2016-10-047 in Kyung Hee University Hospital, Kyung Hee University School of Medicine; GBIRB2016-303 in Gachon University Gil Medical Center; CR317013 in Wonju Severance 
Christian Hospital, Yonsei University Wonju College of Medicine; 2016-99 in Dongguk University Ilsan Hospital; a waiver of approval was granted at the last hospital). Patients provided written informed or verbal consent according to the approval of the IRB and this study complied with the Declaration of Helsinki.

\section{Questionnaire}

Patient satisfaction with MDT care was measured by a simple questionnaire containing 10 key questions about personal satisfaction. The key questions were as follows: (1) Is this the first time you have received MDT care?; (2) Did you have enough time to discuss with the doctors?; (3) Was the process of receiving MDT care easy and straightforward?; (4) Did the doctors who attended the MDT care provide easy and comprehensible explanations?; (5) Did the doctors listen carefully to your words?; (6) Did the doctors provide a sincere and satisfactory answer to your question?; (7) Did your confidence in the management plan of the doctors change after MDT care?; (8) What differences do you find compared with visits delivered by individual departments?; (9) What do you think should be improved in MDT care?; (10) How many points on a 10-point scale would you give for your MDT care? Questionnaire items 2 to 7, pertaining to the subjective opinion of the patient, were answered semi-quantitatively by one of four options on a graded scale, whereas items 8 and 9 were answered freely.

\section{RESULTS}

\section{Trend of MDT care}

The HIRA cohort comprised patients treated by two MDT types based on the number of doctors who participated (four-department participation and five-department participation types) depending on the insurance claim. There was a time gap in the statistical work of the HIRA database. Thus, the data search for our study was possible up to December 2016. The four-department participation type comprised 525 cases in August 2014, when the Korean government began reimbursing MDT care. The case number increased to 2,468 and 3,031 in 2015 and 2016, respectively, showing a rapid and continuous increase the following year (Fig. 1A). The most common age group was between 60 and 69 years in
2016 (Fig. 1B). The five-department participation type showed a similar pattern. The case numbers also rapidly increased to $1,699,7,815$, and 8,143 in 2014, 2015, and 2016, respectively (Fig. 1A). The largest age group in 2016 was 50 to 59 years (Fig. 1 C). The number of cases by region was highest in Seoul, followed by Gyeonggi-do. The most common type of cancer during this period was breast cancer $(23.8 \%, 3,640 / 15,283)$ followed by colorectal (19.1\%), lung (12.0\%), and stomach (7.4\%) cancers, which corresponded to incidences, according to the annual cancer statistics of Korea in 2015 [14], of 18.9\% (3,640/19,219), $10.9 \%(2,923 / 26,790), 7.5 \%(1,831 / 24,267)$, and $3.8 \%(1,124 / 29,207)$, respectively.

\section{Characteristics of MDT}

For a more detailed characterization of patients and MDT care, we collected and analyzed information from the Representative Cohort. The total number of registered patients was 1,032. Among these patients, 359 completed a prospective survey of patient satisfaction with MDT care. The patients' social and clinical information is detailed in Table 1 . The patients were mostly married with a good performance status. Of 365 patients with available information on MDT care attendance, $85 \%$ (312/365) participated in MDT cares with a family member, such as their spouse, offspring, or parent, suggesting that family support is an important value in Korea. MDT care was requested mainly by the surgery department, including breast and gastrointestinal surgeons, a finding consistent with the size of this department in the HIRA cohort. The aims of MDT care were mainly deciding further treatment planning (99.7\%) and explaining the disease status and predicting prognosis (33.5\%). The actual number of doctors who participated ranged from four to eight, with five being the most common (70.0\%). The time required for MDT-based decision making was typically 10 to 30 minutes, although some cases lasted more than 30 minutes (0.3\%). The final decision made based on MDT care led to a change in the management plan for $17.4 \%$ of patients (Table 2 ).

\section{Satisfaction with MDT care}

The responses to the survey are summarized in Table 3. The overall satisfaction with MDT care was very high, according to the responses to all questions, including sufficient time provided to discuss the treatment plan 

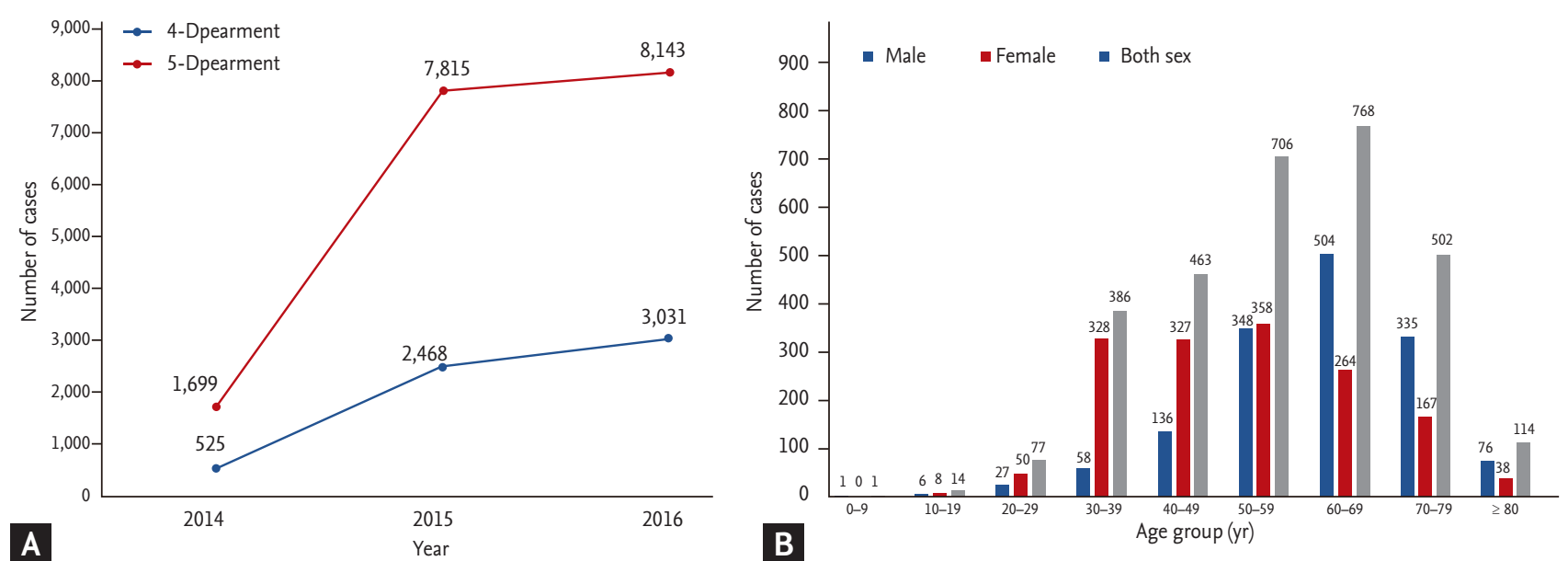

Figure 1. (A) Number of multidisciplinary team implementations according to department participation, by year, from the Health Insurance Review and Assessment Service cohort. (B) Number of cases per age group in the four-department participation category in 2016 . (C) Number of cases per age group in the five-department participation category in 2016 .

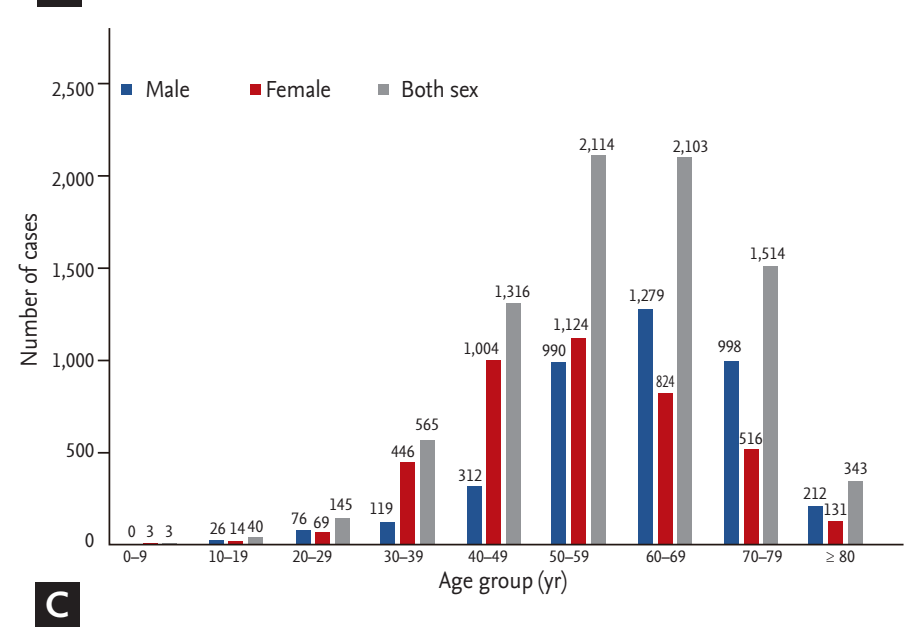

with the MDT, easy accessibility and explanation by the MDT, careful attention to the patient's concerns, satisfactory answers to the patient's questions, and trusting the health professionals involved in MDT care. The mean satisfaction score based on a scale of o to 10 was 9.6. The answers to items 8 and 9, which were required to describe the subjective opinion were summarized separately (Supplementary Table 1).

\section{DISCUSSION}

Our findings showed that the frequency of using MDT care has increased rapidly since reimbursement for MDT care by the NHIS began. In addition, we found that MDT care is operating very well and produces high levels of satisfaction from patient perspectives. The clin- ical presentation of cancer patients varies greatly from individual to individual. Thus, cancer care is often very complex and challenging to many doctors. Various clinical guidelines have been developed to help and guide optimal decision making for oncologists. However, some guidelines have proven to be untrustworthy after critical review [15]. Furthermore, standard guidelines often cannot be applied to cancer patients with atypical clinical features. Both evidence-based principles and expert-opinion-based practice are needed to achieve optimal decision making [16].

According to a report by the National Cancer Action Team in the UK regarding the characteristics of effective cancer treatment, MDT is beneficial for all cancer types [3]. This was supported by a study showing strong agreement between MDT members who participated in the management of different types of tumors [17]. Over 
Table 1. Patient characteristics $(n=1,032)$

\begin{tabular}{|c|c|}
\hline Characteristic & Value \\
\hline Age & $60(3-92)$ \\
\hline \multicolumn{2}{|l|}{ Sex } \\
\hline Male & $551(53 \cdot 4)$ \\
\hline Female & $481(46.6)$ \\
\hline \multicolumn{2}{|l|}{ ECOG } \\
\hline 0 & $169(16.4)$ \\
\hline 1 & $426(41.3)$ \\
\hline 2 & $17(1.6)$ \\
\hline 3 & $2(0.2)$ \\
\hline Unknown & $418(40.5)$ \\
\hline \multicolumn{2}{|l|}{ Stage at initial diagnosis } \\
\hline I & $118(11.4)$ \\
\hline II & $179(17 \cdot 3)$ \\
\hline III & $193(18.7)$ \\
\hline IV & $136(13.2)$ \\
\hline Unknown & $406(39.3)$ \\
\hline \multicolumn{2}{|l|}{ Stage at start of MDT care } \\
\hline $\mathrm{I}$ & $94(9.1)$ \\
\hline II & $155(15.0)$ \\
\hline III & $164(15.9)$ \\
\hline IV & $210(20.3)$ \\
\hline Unknown & $409(39.6)$ \\
\hline \multicolumn{2}{|l|}{ Past treatment } \\
\hline Prior surgery only & $477(46.2)$ \\
\hline Prior chemotherapy only & $45(4 \cdot 4)$ \\
\hline Prior radiotherapy only & $13(1.3)$ \\
\hline Prior surgery and chemotherapy & $66(6.4)$ \\
\hline Prior surgery and radiotherapy & $8(0.8)$ \\
\hline Prior chemotherapy and radiotherapy & $40(3.9)$ \\
\hline All of above & $24(2.3)$ \\
\hline None of these & $307(29.7)$ \\
\hline Others & $52(5.0)$ \\
\hline \multicolumn{2}{|l|}{ Cancer type } \\
\hline Head and neck & $319(30.9)$ \\
\hline Colorectal & $161(15.6)$ \\
\hline Hepatopancreatobiliary & $158(15 \cdot 3)$ \\
\hline Lung & $105(10.2)$ \\
\hline Breast & $97(9.4)$ \\
\hline Gastric & $76(7 \cdot 4)$ \\
\hline Urology & $38(3.7)$ \\
\hline Gynecology & $34(3.3)$ \\
\hline Lymphoma & $20(1.9)$ \\
\hline Esophagus & $11(1.1)$ \\
\hline Sarcoma & $6(0.6)$ \\
\hline Others & $7(0.7)$ \\
\hline
\end{tabular}

Relationship between patient and involved family member Spouse and/or offspring $271(26.3)$ Parents $4(0.4)$ Others $37(3.6)$

Unknown $667(64.6)$

No family member $53(5.1)$

Values are presented as median (range) or number (\%). ECOG, Eastern Cooperative Oncology Group; MDT, multidisciplinary team.
Table 2. Characteristics of multidisciplinary team care $(n=1,032)$

\begin{tabular}{lc}
\hline Characteristic & No. $(\%)$ \\
\hline Consulting department & $366(35.5)$ \\
\hline General Surgery & $183(17.7)$ \\
\hline Head and Neck Surgery & $168(16.3)$ \\
\hline Gastroenterology & $144(14.0)$ \\
\hline Hemato-Oncology & $89(8.6)$ \\
\hline Pulmonology & $24(2.3)$ \\
\hline Urology & $9(0.9)$ \\
\hline Radiation Oncology & $2(0.2)$ \\
\hline Thoracic Surgery & $47(4.5)$ \\
\hline Others
\end{tabular}

Aim of MDT care

$\begin{array}{lc}\text { Decision of further treatment plan } & 679(65.8) \\ \begin{array}{l}\text { Decision of further treatment plan } \\ \text { and explanation of disease }\end{array} & 197(19.1) \\ \begin{array}{l}\text { Decision of further treatment plan } \\ \text { and prediction of prognosis }\end{array} & 7(0.7) \\ \text { Prediction of prognosis } & 1(0.1) \\ \text { All of above } & 145(14.1) \\ \text { Unknown } & 3(0.3)\end{array}$

No. of doctors

\begin{tabular}{|cc|}
\hline 4 & $140(13.6)$ \\
\hline 5 & $722(70.0)$ \\
6 & $130(12.6)$ \\
7 & $37(3.6)$ \\
\hline 8 & $1(0.1)$ \\
\hline Unknown & $2(0.2)$ \\
\hline MDT care time, min & \\
\hline
\end{tabular}

\begin{tabular}{lc}
\hline 5-10 & $25(2.4)$ \\
\hline $10-20$ & $308(29.8)$ \\
\hline $20-30$ & $110(10.7)$ \\
\hline More than 30 & $3(0.3)$ \\
Missing & $586(56.5)$ \\
\hline Change of management plan after MDT care & \\
\hline Yes & $180(17.4)$ \\
\hline No & $840(81.4)$ \\
\hline Unknown & $12(1.2)$ \\
\hline
\end{tabular}

MDT, multidisciplinary team. 
Table 3. Patient-reported satisfaction survey for multidisciplinary team care $(n=1,032)$

\begin{tabular}{|c|c|c|}
\hline Question & Answer & No. (\%) \\
\hline \multirow[t]{3}{*}{ Q1. Did you receive the MDT care for the first time? } & Yes & $333(92.8)$ \\
\hline & No & $21(5.8)$ \\
\hline & Missing & $5(1.4)$ \\
\hline \multirow[t]{5}{*}{ Q2. Did you have enough time allocated during MDT care? } & Strongly yes & $169(47 \cdot 1)$ \\
\hline & Yes & $179(49.9)$ \\
\hline & No & $3(0.8)$ \\
\hline & Strongly no & $3(0.8)$ \\
\hline & Missing & $5(1.4)$ \\
\hline \multirow[t]{5}{*}{ Q3. Was the procedure easy and simple? } & Strongly yes & $207(57.7)$ \\
\hline & Yes & $141(39 \cdot 3)$ \\
\hline & No & $4(1.1)$ \\
\hline & Strongly no & $2(0.6)$ \\
\hline & Missing & $5(1.4)$ \\
\hline \multirow[t]{5}{*}{ Q4. Did the doctors explain it easily and understandably? } & Strongly yes & $234(64 \cdot 3)$ \\
\hline & Yes & $122(34.0)$ \\
\hline & No & $1(0.3)$ \\
\hline & Strongly no & o \\
\hline & Missing & $5(1.4)$ \\
\hline \multirow[t]{5}{*}{ Q5. Did the doctors listen carefully to your questions? } & Strongly yes & $233(64.9)$ \\
\hline & Yes & $121(33.7)$ \\
\hline & No & o \\
\hline & Strongly no & o \\
\hline & Missing & $5(1.4)$ \\
\hline \multirow[t]{5}{*}{ Q6. Did the doctors give you a satisfactory answer to your question? } & Strongly yes & $242(67.4)$ \\
\hline & Yes & $110(30.6)$ \\
\hline & No & $2(0.6)$ \\
\hline & Strongly no & o \\
\hline & Missing & $5(1.4)$ \\
\hline \multirow{4}{*}{$\begin{array}{l}\text { Q7. Did your trust in the diagnosis and treatment strategy of doctors change after } \\
\text { MDT care? }\end{array}$} & More confidence & $318(88.6)$ \\
\hline & No change & $32(8.9)$ \\
\hline & Lower confidence & $3(0.8)$ \\
\hline & Missing & $6(1.7)$ \\
\hline \multirow[t]{6}{*}{$\begin{array}{l}\text { Q10. On a scale of o to } 10 \text {, how many points would you give your MDT in } \\
\text { your satisfaction score? }\end{array}$} & $\begin{array}{l}5 \\
6\end{array}$ & $\begin{array}{l}1(0.3) \\
2(0.6)\end{array}$ \\
\hline & 7 & $12(3 \cdot 3)$ \\
\hline & 8 & $34(9.5)$ \\
\hline & 9 & $105(29.2)$ \\
\hline & 10 & $200(55.7)$ \\
\hline & Missing & $5(1.4)$ \\
\hline
\end{tabular}

MDT, multidisciplinary team. 
$80 \%$ of all patients with cancer in the UK are managed by MDTs [18]; however, our study showed that less than approximately $20 \%$ of cancer patients in Korea have received MDT care, suggesting that MDT implementation is still in its infancy in Korea. Moreover, the frequency of MDT care in Korea varied by region (being most frequent in Seoul), which could be because of the increased number of university hospitals located in the metropolitan area. On the other hand, there is still doubt concerning which patients would benefit from MDT care. It has been shown that, although many doctors prefer to meet most of their new patients as an MDT, it is not always necessary, especially for early stage or low-risk patients $[19,20]$. Unlike other counties, MDT care in Korea is characterized by the fact that the patient must attend the meeting with his or her doctors [20,21]. In addition, much administrative effort is required to coordinate the schedule of multiple doctors and participating patients. Therefore, to make MDT care as efficient and successful as possible, it is essential to administer the physicians' limited time to patients who will benefit the most from an MDT approach.

Based on the survey conducted in the Representative Cohort, the primary aim of MDT care was to devise a management plan for a given clinical situation. It was found that the diagnosis and/or management plan often changes after MDT care for a substantial proportion of patients. According to some studies, $12 \%$ to $38 \%$ of patients experienced a change in their diagnosis or management plan after MDT care [22-26]. However, the rate of such a change was less than $10 \%$ [27-29] or even negligible [30] in other reports. In our study, the rate of change was $17.4 \%$, which was consistent with previous studies but slightly lower than we expected. This could be explained by the smaller proportion of newly diagnosed patients who underwent MDT care. In our study, $70.3 \%$ of patients received at least one type of treatment before MDT care, compared with $29.7 \%$ who did not. It was assumed that this $29.7 \%$ of patients received MDT care at the time of initial diagnosis. Considering that MDT care at the time of initial diagnosis usually leads to a substantial change in the treatment plan as a result of a revised preoperative stage or histologic results [22,29,3133], the small proportion of newly diagnosed patients in our cohort may explain the relatively low rate of change in the treatment plan after MDT care.
Further support for providing MDT care came from the ability to provide a detailed explanation to the patient regarding their disease status (19\% of all respondents). Some respondents reported that it was easier to accept and understand the doctors' explanation because the MDT members worked together to discuss with the patient. Because MDT care is usually requested when a patient's disease status has drastically changed or worsened, such as recurrence detected during a regular follow-up, the patient often does not trust the doctor's diagnosis or occasionally seeks a second opinion rather than accept the bad news. Thus, it may be assumed that delivering bad news is easier when conducted by several doctors together. Many researchers have consistently reported that MDT care is necessary and helpful in communicating bad news [34-37]. Additionally, Korean MDTs should involve the patient and/or their family because of reimbursement indications, whereas MDTs in the UK rarely invite the patient because of concerns regarding the inability to speak frankly about the prognosis and because of time constraints [38]. However, considering that the purpose of MDT care is not only for effective decision making but also for easier communication between the patient and physician, MDT care involving patient participation may be better than that not involving the patient. If patients do not participate in the MDT, the meeting is typically similar to a tumor board, where doctors discuss the clinical case without the patient. In this way, it is possible to discuss many cases quickly in a short period of time, but establishing a treatment plan without considering the patients' preferences and individual circumstances or addressing their concerns may decreases patient satisfaction.

According to the prospective survey, the overall satisfaction of cancer patients in Korea receiving MDT care was substantially high. As shown in Table 3, most patients responded that there was sufficient time to discuss with the MDT, easy accessibility to the MDT, careful attention to the patient's concerns and satisfactory answers to the patient's questions by the MDT, and trust of the health professionals in the MDT. The patient's perception of the doctor's empathy and the time allotted to discuss with the doctors showed a positive correlation with the patient's satisfaction [39,40]. In our study, the time allotted for discussion between the patient and MDT was approximately 20 minutes, which 
was thought to be sufficient.

When MDT care was first introduced in Korea in 2014, the NHIS provided reimbursement only for MDT care given to outpatients by doctors from at least four or five departments. This contrasted with the European guideline "Policy statement on multidisciplinary cancer care" released to help local institutes establish and implement optimal MDT care [5].

Fortunately, reimbursement for MDT care has been expanded to inpatients as well as MDTs consisting of doctors from only three departments, suggesting encouragement of MDT care by the Korean government. Meanwhile, a recent European MDT policy statement mentioned the importance of psychosocial support in addition to diagnosis and treatment, which emphasized the role of psychiatrists in an MDT [5]. However, our survey showed that no patient received MDT care involving a psychosocial specialist. Likewise, discussion of survival and/or a palliative care team should also be incorporated into MDT care, but such incorporation was also not observed in our survey.

Our study had several limitations. Whether the four hospitals included in the Representative Cohort sufficiently reflected the entire status of MDT care in Korea is debatable considering selection bias. Second, there was a substantial amount of missing data, including the relationships between the patient and involved family members, number of family members receiving MDT care, Eastern Cooperative Oncology Group (ECOG) performance status, and the period of MDT care.

In conclusion, the application of MDT care for cancer patients in Korea has grown rapidly since reimbursement for MDT care by the NHIS began. The format for MDT care in Korea is patient-centered with prominent family support, and patient satisfaction was generally excellent. Further research is needed to determine which patients can gain the most benefit from a MDTbased treatment approach to make MDT more efficient and help it to expand successfully in Korea.

\section{KEY MESSAGE}

1. The application of multidisciplinary team (MDT) care for cancer patients in Korea has grown rapidly since reimbursement for MDT care by the National Health Insurance Service began.

2. A MDT was often requested by a surgeon, mainly for the purpose of establishing the treatment plan. All MDTs were attended by the patients with or without their family.

3. After incorporating MDT-based decision making, the treatment plan changed for $17.4 \%$ of patients.

4. The results of the questionnaire showed very high patient satisfaction, with an average score of 9.6 out of 10 points.

\section{Conflict of interest}

No potential conflict of interest relevant to this article was reported.

\section{Acknowledgments}

This study was supported by a grant from Kyung Hee University in 2018 (KHU-20180924).

The Korean Association for Clinical Oncology (KACO) also supported this study with a 2016 Academic Awards grant. The KACO was renamed the Korean Society of Medical Oncology (KSMO) as of 2018.

This study was presented in part at the 2017 annual meeting of the Korean Association of Clinical Oncology (KACO) in Seoul and in a Mini-oral session at the European Society of Medical Oncology (ESMO)-ASIA 2018 in Singapore.

\section{REFERENCES}

1. Ubel PA, Angott AM, Zikmund-Fisher BJ. Physicians recommend different treatments for patients than they would choose for themselves. Arch Intern Med 2011;171:630-634.

2. Hewitt M, Breen N, Devesa S. Cancer prevalence and survivorship issues: analyses of the 1992 National Health Interview Survey. J Natl Cancer Inst 1999;91:1480-1486.

3. National Health Service (NHS); National Cancer Action Team. The characteristics of an effective multidisciplinary team (MDT) [Internet]. London (UK): National Cancer Intelligence Network, 2010 [cited 2019 Nov 8]. 
Available from: www.ncin.org.uk/view?rid=136.

4. Saini KS, Taylor C, Ramirez AJ, et al. Role of the multidisciplinary team in breast cancer management: results from a large international survey involving 39 countries. Ann Oncol 2012;23:853-859.

5. European Partnership Action Against Cancer consensus group, Borras JM, Albreht T, et al. Policy statement on multidisciplinary cancer care. Eur J Cancer 2014;50:475480.

6. Korman H, Lanni T Jr, Shah C, et al. Impact of a prostate multidisciplinary clinic program on patient treatment decisions and on adherence to NCCN guidelines: the William Beaumont Hospital experience. Am J Clin Oncol 2013;36:121-125.

7. Liao CT, Kang CJ, Lee LY, et al. Association between multidisciplinary team care approach and survival rates in patients with oral cavity squamous cell carcinoma. Head Neck 2016;38 Suppl 1:E1544-E1553.

8. Pillay B, Wootten AC, Crowe H, et al. The impact of multidisciplinary team meetings on patient assessment, management and outcomes in oncology settings: a systematic review of the literature. Cancer Treat Rev 2016;42:56-72.

9. Kelly SL, Jackson JE, Hickey BE, Szallasi FG, Bond CA. Multidisciplinary clinic care improves adherence to best practice in head and neck cancer. Am J Otolaryngol 2013;34:57-6o.

10. Jung SM, Hong YS, Kim TW, et al. Impact of a multidisciplinary team approach for managing advanced and recurrent colorectal cancer. World J Surg 2018;42:2227-2233.

11. Lee B, Kim K, Choi JY, et al. Efficacy of the multidisciplinary tumor board conference in gynecologic oncology: a prospective study. Medicine (Baltimore) 2017;96:e8089.

12. Kim DY, Lee YG, Kim BS. Survey of medical oncology status in Korea (SOMOS-K): a national survey of medical oncologists in the Korean association for clinical oncology (KACO). Cancer Res Treat 2017;49:588-594.

13. Lee YG, Oh S, Kimm H, et al. Practice patterns regarding multidisciplinary cancer management and suggestions for further refinement: results from a national survey in Korea. Cancer Res Treat 2017;49:1164-1169.

14. Jung KW, Won YJ, Kong HJ, Lee ES; Community of Population-Based Regional Cancer Registries. Cancer statistics in Korea: incidence, mortality, survival, and prevalence in 2015. Cancer Res Treat 2018;50:303-316.

15. Reames BN, Krell RW, Ponto SN, Wong SL. Critical evaluation of oncology clinical practice guidelines. J Clin On- col 2013;31:2563-2468.

16. Gnant M. Guidelines: usefulness and limitations. Breast Care (Basel) 2013;8:172-173.

17. Lamb BW, Sevdalis N, Taylor C, Vincent C, Green JS. Multidisciplinary team working across different tumour types: analysis of a national survey. Ann Oncol 2012;23:1293-1300.

18. Griffith C, Turner J. United Kingdom national health service, cancer services collaborative "improvement partnership", redesign of cancer services: a national approach. Eur J Surg Oncol 2004;30 Suppl 1:1-86.

19. Lamb BW, Jalil RT, Sevdalis N, Vincent C, Green JS. Strategies to improve the efficiency and utility of multidisciplinary team meetings in urology cancer care: a survey study. BMC Health Serv Res 2014;14:377.

20. Taylor C, Finnegan-John J, Green JS. "No decision about me without me" in the context of cancer multidisciplinary team meetings: a qualitative interview study. BMC Health Serv Res 2014;14:488.

21. Bunnell CA, Weingart SN, Swanson S, Mamon HJ, Shulman LN. Models of multidisciplinary cancer care: physician and patient perceptions in a comprehensive cancer center. J Oncol Pract 2010;6:283-288.

22. Greer HO, Frederick PJ, Falls NM, et al. Impact of a weekly multidisciplinary tumor board conference on the management of women with gynecologic malignancies. Int J Gynecol Cancer 2010;20:1321-1325.

23. Wheless SA, McKinney KA, Zanation AM. A prospective study of the clinical impact of a multidisciplinary head and neck tumor board. Otolaryngol Head Neck Surg 2010;143:650-654.

24. Kurpad R, Kim W, Rathmell WK, et al. A multidisciplinary approach to the management of urologic malignancies: does it influence diagnostic and treatment decisions? Urol Oncol 2011;29:378-382.

25. De Ieso PB, Coward JI, Letsa I, et al. A study of the decision outcomes and financial costs of multidisciplinary team meetings (MDMs) in oncology. Br J Cancer 2013;109:2295-2300.

26. van Hagen $P$, Spaander MC, van der Gaast A, et al. Impact of a multidisciplinary tumour board meeting for upper-GI malignancies on clinical decision making: a prospective cohort study. Int J Clin Oncol 2013;18:214-219.

27. Santoso JT, Schwertner B, Coleman RL, Hannigan EV. Tumor board in gynecologic oncology. Int J Gynecol Cancer 2004;14:206-209. 
28. Cohen P, Tan AL, Penman A. The multidisciplinary tumor conference in gynecologic oncology: does it alter management? Int J Gynecol Cancer 2009;19:1470-1472.

29. Chinai N, Bintcliffe F, Armstrong EM, Teape J, Jones BM, Hosie KB. Does every patient need to be discussed at a multidisciplinary team meeting? Clin Radiol 2013;68:780784 .

30. Acher PL, Young AJ, Etherington-Foy R, McCahy PJ, Deane AM. Improving outcomes in urological cancers: the impact of "multidisciplinary team meetings". Int J Surg 2005;3:121-123.

31. Davies AR, Deans DA, Penman I, et al. The multidisciplinary team meeting improves staging accuracy and treatment selection for gastro-esophageal cancer. Dis Esophagus 2006;19:496-503.

32. Freeman RK, Van Woerkom JM, Vyverberg A, Ascioti AJ. The effect of a multidisciplinary thoracic malignancy conference on the treatment of patients with lung cancer. Eur J Cardiothorac Surg 2010;38:1-5.

33. Newman EA, Guest AB, Helvie MA, et al. Changes in surgical management resulting from case review at a breast cancer multidisciplinary tumor board. Cancer
2006;107:2346-2351.

34. Aein F, Delaram M. Giving bad news: a qualitative research exploration. Iran Red Crescent Med J 2014;16:e8197.

35. Kissane DW, Bylund CL, Banerjee SC, et al. Communication skills training for oncology professionals. J Clin Oncol 2012;30:1242-1247.

36. Otani H, Morita T, Esaki T, et al. Burden on oncologists when communicating the discontinuation of anticancer treatment. Jpn J Clin Oncol 2011;41:999-1006.

37. Saviani-Zeoti F, Petean EB. Breaking bad news: doctors' feelings and behaviors. Span J Psychol 2007;10:380-387.

38. Whiteman AR, Dhesi JK, Walker D. The high-risk surgical patient: a role for a multi-disciplinary team approach? $\mathrm{Br}$ J Anaesth 2016;116:311-314.

39. Hojat M, Louis DZ, Maxwell K, Markham FW, Wender RC, Gonnella JS. A brief instrument to measure patients' overall satisfaction with primary care physicians. Fam Med 2011;43:412-417.

40. Ogden J, Bavalia K, Bull M, et al. "I want more time with my doctor": a quantitative study of time and the consultation. Fam Pract 2004;21:479-483. 
Supplementary Table 1. Responses to questions 8 and 9

Q8. What differences did you observe between individual departments in MDT care?

\section{Statement}

Positive opinion

It was good that specialists from different fields presented their diagnoses together.

Detailed descriptions by multiple doctors helped me to understand the progress of the illness and to anticipate future treatments and results.

The doctors' explanations were trustworthy.

Meeting with doctors from various departments at the same time was very convenient for me.

I felt that MDT care was authentic.

5

I was very satisfied with MDT care.

Listening to the doctors' explanations while watching the video helped me to understand my present condition.

I was happy to be able to recognize my illness and think about how to cope with it in the future.

Negative opinion

There was no significant difference between general individual care and MDT care.

I feel that MDT care was burdensome in some ways.

Total

8

1

124

Q9. What aspects of MDT care should be improved?

Statement

It is very satisfactory; no further improvement is needed.

27

Explanations should be easier to understand.

More time should be allocated to discuss the results.

A presentation made by multiple doctors is too complex; I would prefer one doctor to offer a single, comprehensive opinion.

I was disappointed because additional examinations were required after MDT.

MDT care was unfamiliar.

I would have preferred to receive MDT at an earlier stage of my cancer.

Total
8

3

1

1

1

1

42

MDT, multidisciplinary team. 